\title{
EFFECTIVENESS AND OPTIMIZATION OF HARBOUR TUG FLEET
}

\author{
Oleksandr Bondarenko ${ }^{1}$, Valery Nekrasov ${ }^{2}$, Oleksii Yastreba $^{3}$ \\ ${ }^{1,2,3}$ Admiral Makarov National University of Shipbuilding \\ Mykolaiv, Ukraine, Geroev Ukraine Avenue 9, 54025 \\ ${ }^{1}+380982441295$, oleksandr.bondarenko@nuos.edu.ua \\ ${ }^{2}+380636120941$, valery.nekrasov@nuos.edu.ua \\ 3 +380958104860, oleksii.yastreba@nuos.edu.ua
}

Determination of efficiency and optimization harbour tug fleet is based on simulation of fleet work and usage for this the methods of ship dynamics and probability theory. Visiting the port transport vessels of possible types is considered as random stream of given intensity. This stream is distributed over the berths. Productivities of berths are given random variables. Random variables are also characteristics of weather conditions in the harbour basin. Tug fleet is represented by the collection of existing port tugs of different types. Work of tugs is determined by operations of approaching to ships, escorting theirs in the near-port waters, posting on the approach channels, transportation within the port waters, berthing, unberthing and going out the ship from the port with the repetition of functioning operations in reverse order. Selection of tugs to service the next arriving or departing ship is dependent from the intensity of the current weather conditions in the port and busyness of tugs in operations with other ships. Work fleet is considered on the conditional time interval of one year. In this time the efficiency of the tug fleet is defined by economic indexes of fulfilment of all towing operations and operations on maintenance tugs. Optimization of the fleet composition is carried out according to the criteria required minimum total bollard pull, low cost and high profit. Based on performed research a program for calculating the efficiency and optimization of the port towing fleet is composed. The program can be adapted to any port with whatever types of tugs.

Keywords: simulation, optimization, harbour tug, software, port

\section{Introduction}

Recently observed evolution of port tugs is characterized by a continuous increase in their power and improved handling characteristics. The dimensions of the port tugs are also continuously changing. More powerful engines are installed in smaller hulls. Small, very powerful and manoeuvrable tugs become necessary for the ports development, as their space with an increase in the berths productivity and the increase in served vessels dimensions remains limited.

Following the increase in the port tugs power, a relative decrease in their number of vessels servicing, both per vessel and as a part of the port tug fleet, is observed everywhere.

In this regard, it is suggested that a reduction in the tugs number due to more powerful units' introduction may have a generally negative effect on ports. The gist of these hypotheses is the following (Hensen, 2003a):

- a reduced number of tugs can cause problems in cases of severe weather conditions or peaks in the vessels motions;

- commissioning of more powerful tugs, leading to a reduction in the number of tugs used on one vessel, for example, from four to two units, will lead to additional risks that can be compensated only by the corresponding increase in the reliability of the technical means that are used;

- tugs, besides, should be suitable in sizes to the vessel dimensions. This means that small vessels should preferably be operated by small tugs;

- the replacement of several small tugs with a more powerful tug may benefit the owner of the tug fleet, thanks to a reduction in overall costs and a reduction in the cost of maintaining the teams. However, the commissioning of more powerful tugs will not automatically mean that the captains of vessels entering the port will order fewer tugs. In such cases, a towing company that has invested heavily in the development of its fleet may suffer losses, as vessels using an increased number of tugs pay the same tug charges.

Despite these hypotheses, the transition to the powerful harbour tugs use is being carried out everywhere. This is due to the stakeholders' economic priorities (Hensen, 2003a). The ship owner, for example, usually wants to accelerate port operations, which in turn leads to the use of more powerful 
tugs. The port, on the one hand, attempts to use more powerful tugs in connection with the expected reduction in costs, but on the other, it fears not to have the very large and powerful tugs reusing and not to return investments aimed at developing its tug fleet.

The solution of these problems, obviously, should correspond to the balance that forms in the port functional operations environment. As each port is significantly different from one another, the requirements for the number and power of the introduced port tugs must be formed individually. At the same time, the use of more powerful tugs, associated with increased investment in their acquirement and the increase in operating costs, is justified with a corresponding increase in the port productivity and the maintenance of vessels with characteristics due to increased productivity.

The trend of using more and more powerful tugs also causes difficulties in estimating the values of their power and bollard pull from the point of view of ensuring the safety of vessel steering in the port. A proper evaluation of such values is especially important for large vessels with high motion resistance, the number of which is continuously increasing. These values are especially important for the port authorities to know when vessels arrive, for which towing support should be carried out. In such cases, the solution of this problem is possible by developing the appropriate software.

To determine the current tug support of the port, the International Maritime Organization recommends the publication of the Navigation Institute, London, «Use of the Tug at the Port - Practical Manual» (IMO, 2003), (Hensen, 2003b). The main position of this manual is justification that the port's towage should be formed not only depending on the purpose and dimensions of mooring vessels, but also in accordance with geographical location and specific climatic conditions of the port territory.

The closest to the topic of the article is the "Technique of choosing the optimal types and number of tugs for the seaport", which was developed by T.F. Alyavdina (1986). Since then, the tugs themselves have significantly changed - in the areas of compactness, power and manoeuvrability noted above, and the models of their functioning - in the direction of a more detailed account of interaction with environment, taking into account the randomness of the appearance of vessels entering the port and the weather factors of operation, functioning according to the criteria of a market economy.

The purpose of the article is to develop the algorithms for choosing optimal structure of the port tug fleet, which provides a significant increase in productivity and profitability of towing operations.

\section{Methodology description}

\subsection{Problem statement}

Based on recommendations (IMO, 2003), (Hensen, 2003b), the authors developed an appropriate method for determining the forces acting on vessels mooring in seaports (Bondarenko et al., 2016). The development of method is carried out by simulating the processes of escorting and docking/sailing of vessels in wind, wave and current conditions (Bondarenko et al., 2016).

To determine the necessary composition and characteristics of the port tugs serving a given stream of vessels, an appropriate model for the functioning of the port's tug fleet has been made. The model is based on the methods of queuing theory (Gnedenko and Kovalenko, 2007) (Saaty, 1961), (Stewart, 2009), simulation (Law, 2015), (Chan, 2013) and ship dynamics (Lewandowski, 2003). At the same time, the approach channel, berths and tugs are represented by servicing devices that can be in two states - free or work, and vessel arrivals to the port - by requests distributed on berths. In general, the port berths complex is reflected by a multi-channel queuing system, which is in variable (random) weather operating conditions with a random flow of requests.

For each berth, a random time is generated for the appearance of the next vessel (service request) that delivered the goods to the port or arrived for loading. For the received request, depending on vessel type, its deadweight and accidental weather conditions at the time of manoeuvre operations, the total required bollard pull of the port tugs is determined and their number is selected from considered composition of the port tug fleet, taking into account the employment of tugs in operations with other vessels. The possibility of entering the port is checked. For this, the following conditions must be carried out: the channel must be free, the berth is free, and there are a sufficient number of tugs of the required bollard pull.

If these conditions are carried out, the following stages of towing operations are simulated: escorting or escorting the vessel along approach channel, transporting it to the berth and mooring. If conditions for entering the port are not carried out, the request is placed in the service queue, and the vessel is placed in the anchorage. 
The time of staying at the berth during loading and unloading operations is modelled depending on the quay equipment production, which is also a random value.

After loading or unloading the vessel, a similar sequence of operations is carried out to remove her from the port. At the end of the time of manoeuvre operations with vessel leaving the port, the request leaves the model; the tugs and the channel are released. Simulation process is carried out simultaneously to all berths on an interval of time equal to a calendar year, with a time step equal to one minute.

The developed model of functioning is added by the port tugs efficiency indicators calculation block. It is suggested that the income of the tug consists mainly of two components: hourly fee for escorting along the approach channel and payment for mooring operations (towage). For tugs serving gascarriers vessels, additional income is determined by escorting a gas-carrier vessel in coastal waters and on duty near a gas-carrier vessel at its staying at the berth. The operating costs of the port tug include crew expenses, amortization, repairs, maintenance, docking, classification inspection and fuel.

Determination of the optimal characteristics of the tugs and the port tug fleet composition is carried out by solving the optimization problem in which the criterion of optimality considers the minimum of the tug fleet total bollard pull for a given vessel traffic and the maximum of productivity (profit) in the time interval equal to the calendar year. The problem is formulated as follows:

$$
\min _{X \in R^{n}} F(X, C) \text { or } \max _{X \in R^{n}} F(X, C)
$$

subject to a: $g_{j}(X)=0, \quad j=p+1, \ldots, k$,

$$
g_{j}(X) \geq 0, \quad j=1, \ldots, p,
$$$$
x_{i}^{\min } \leq x_{i} \leq x_{i}^{\max }, \quad i=1, \ldots, n,
$$

where $F(X, C)$ - objective function; $X\left(x_{1}, \ldots, x_{n}\right)$ - independent variables vector, $n$ - independent variables number; $k$ - total number of problem constraints; $p$ - problem constraints number in the form of inequalities, $g$ is the vector constraints; $x_{i}^{\min }$ is lower bounds on the independent variable, $x_{i}^{\max }$ is upper bounds on the independent variable; $x_{i}$ is values of the independent variables; $j$ is index for constraints; $i$ is index for independent variables.

The vector of independent variables includes the bollard pull $\left(Z_{i}\right)$ and the number of tugs of the $i$-th type $\left(N_{i}\right)$.

The constraint system of the problem contains the requirements:

- to the definite type tugs number

$N_{i}^{\min } \leq N_{i} \leq N_{i}^{\max }$

where $N_{i}^{\min }=0-$ the $i$-th type tugs minimum number; $N_{i}^{\max }-$ the $i$-th type tugs maximum number;

- to the bollard pull of definite type tugs

$$
Z_{i}^{\min } \leq Z_{i} \leq Z_{i}^{\max }
$$

where $Z_{i}^{\min }$ - the minimum bollard pull of $i$-th type tugs; $Z_{i}^{\max }-$ the maximum bollard pull of $i$-th type tugs.

The main dependencies used in the mathematical model of the fleet of port tugs are described in the work of authors (Bondarenko et al., 2016).

Based on the proposed model of the port tugs functioning and the method for calculating the efficiency characteristics of their work, a program is developed to determine the efficiency of the tug fleet serving the port's predicted vessel traffic. The program takes into account the actual of all listed towing incomes from escort operations, escorts, «mooring», «unmooring» and watch by vessels, as well as the listed items of operating costs. At the same time, fuel costs are determined by the current power costs necessary to develop the required bollard pull ensuring the realization of towing operation in current weather conditions, taking into account the additional forces due to the kinematics of vessel and tugs. 
The developed program has a modular structure. Each module consists of blocks. All modules of the program can be combined into two groups: modules that provide the user interface and modules that realize the methodology for bollard pull, power and number of tugs calculating.

The program interface allows entering the initial data for simulation and the characteristics of the port's towage. The interface of the program is written in accordance with modern requirements for programs of this type.

Modules that realize the methodology for bollard pull, power, number and tugs efficiency characteristics calculating include: "ship_model", "uGeneticAlg". Pascal and Delphi 7 were used for writing the program. The program main menu is showed on Figure 1.

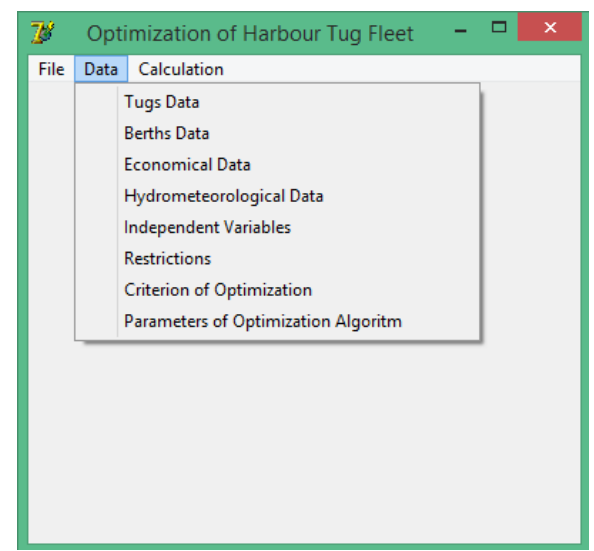

Figure 1. The program main menu

\subsection{Solving the optimization problem. Determination of the optimal modern and perspective towing of the port}

The solution of the optimization problem can be realized in two ways.

The optimization first way. This method requires the selection of the optimal towage from tugs sizes predetermined set.

The selection procedure is carried out in the following sequence.

1. Using «Tug data» command of «Data» menu, the required sizes and characteristics of the tugs applicants are set (Table 1).

Table 1. Characteristics of the tugs

\begin{tabular}{|l|c|c|c|c|}
\hline \multicolumn{1}{|c|}{ Tug name } & Bollard Pull, t & Crew & Power, kW & Speed, knot \\
\hline Equator & 3 & 8 & 165 & 8.0 \\
\hline Boreas & 16 & 8 & 896 & 10.0 \\
\hline Nord & 20 & 8 & 1180 & 11.5 \\
\hline Stan tug 1907 & 30 & 8 & 3132 & 12.8 \\
\hline Yakovtsev & 50 & 8 & 3132 & 12.8 \\
\hline Saveliev & 50 & 8 & 3700 & 8.0 \\
\hline UTN & 50 & 8 & 4200 & 8.0 \\
\hline Ivanov & 65 & 8 & 3700 & 8.0 \\
\hline Moguchiy & 75 & 8 & & \\
\hline
\end{tabular}

2. The data necessary for simulating, data on vessel calls, types of vessels and their characteristics are specified.

3. The following economic indicators are introduced to calculate the tugs efficiency: rate for berthing, cost of one ton of fuel, average salary of crew, rate of depreciation, rate of repairs cost, rate of docking, time of simulation.

4. In addition, hydro meteorological characteristics are entered. Data on the parameters of aerohydrodynamic impact on the vessel due to the presence of current, wind and waves, as well as on the 
kinematic parameters of the vessel's motion, are introduced, which determine the presence of forces of resistance to the vessel's motion and inertial forces at the moment of beginning of its approaching from a distance $40 \mathrm{~m}$ from the pier. For the maximum accessible weather conditions for mooring operations, they are set by the port standards, for less intensive conditions - based on reliable short-term weather forecasts.

5. The process of modelling the port's operation during the considered period is started (the command «Execute» in the «Calculation» menu). In the calculation control window, (Fig. 2), the calculation process is monitored.

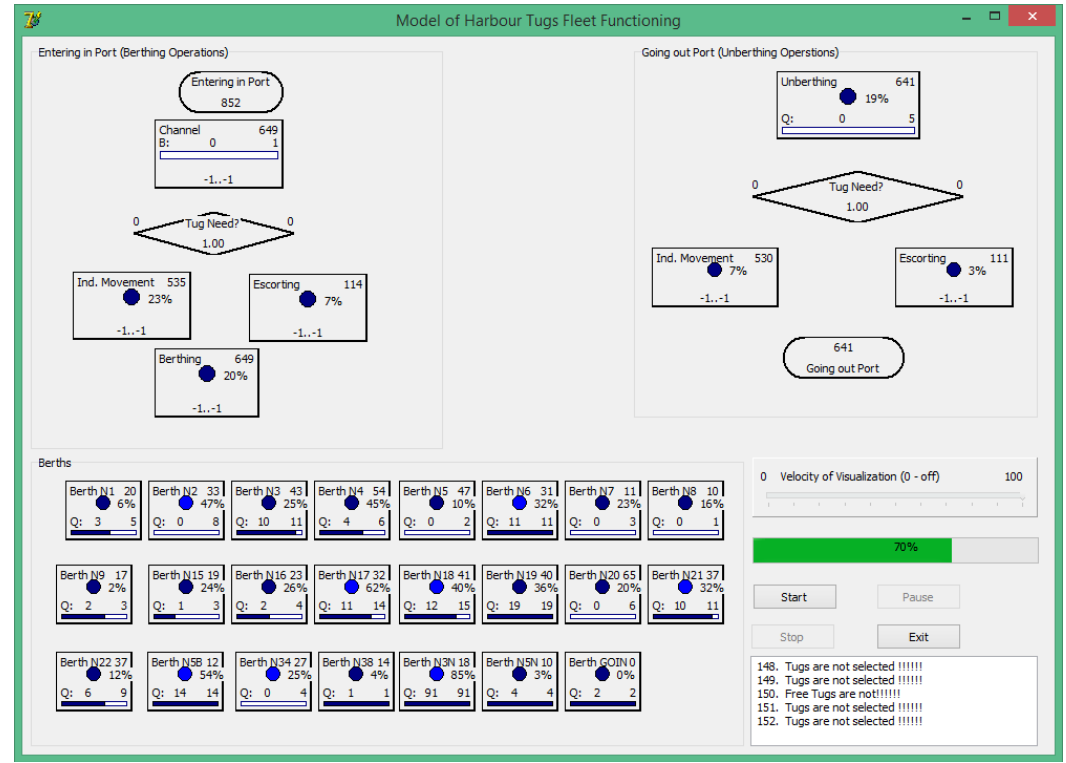

Figure 2. Window for monitoring the escorting of vessels by tugs on the approach channel, their «mooring» and «unmooring» in the existing berth complex and the berth complex of the future

6. After completing the calculation, the «Towing scheme» tab is displayed in the «Calculation results» dialog box, which shows the maximum total bollard pull of tugs developed in operations with the vessel, the «Economy» tab, which corresponds to the total costs and the income of the port's tug fleet, the «Statistics» tab, which indicates the total number of tug calls and the time of their use in hours. Tugs with a low number of calls are practically not used in the port and they can be excluded from the list of modern and prospective towage of the port.

In connection with the fact that the calculation algorithm provides for the selection of the tugs for the efforts that will take place in the towing operation with a particular vessel, in specific weather conditions of the year and the geographical location of the port, and also taking into account limitations such as «the second tug bollard pull cannot be less than half the bollard pull of the first», etc., providing the safety of operations on vessels mooring, the result of the calculation for a given ship traffic and the tug fleet composition provides for an automatic minimization of the fleet total bollard pull over the considered period of time, and, consequently, operations costs minimization and profits maximization based on the results of their carrying out.

The main advantage of this method - is that the choice of the port tug fleet optimal composition is made rather quickly, and the disadvantage is that the optimum composition of tugs is selected from the predefined set of standard sizes of tugs.

The optimization second way. In the second method, the optimization problem is solved in its pure form. It allows you to select for such a given vessel traffic of a tugs sizes set, which provides the maximization of profit.

It is supposed that the composition of harbour tug fleet is characterized by the number of types of tugs, the bollard pull and the number of tugs of each type. The number of tug types is considered a defined value. The bollard pull and the number of tugs of each type are independent variables, the optimal values of which should be determined. The total number of independent variables $n$ is determined by the formula

$n=2 N_{\text {type }}$,

where $N_{\text {type }}$ - the total number of tug types. 
While applying the genetic algorithm, each population (a set of acceptable options for solving the optimization problem) consists of their chromosomes. Each chromosome is an acceptable solution of the optimization task. Such a solution is determined by the vector of independent variables:

$$
X\left(x_{1}, \ldots, x_{n}\right), \quad i=1, \ldots, n,
$$

where the even values of the index $n$ correspond to the number of tugs of type $j$, and the odd ones bollard pull of the tug of type $j$.

The number of acceptable solutions of the optimization task is given by the population size.

The independent variables $X$ vector numerical values are the individual genetic code and should be stored in the computer's memory in the form of a fixed-length line for the selection process realization. There are range of ways to represent numbers (encoding) in genetic operators: decimal, binary, Gray encoding. In this paper, a transformation using the Gray code is applied.

At fitness function calculations, as well as at the optimal solution output, the values are decoded, i.e. converted into numerical values.

The process of searching a solution for this method starts with entering the starting values of independent variables.

At the next stage, a limitations system that sets the area of the allowed values is created.

The procedure for finding the Port_Tugs solution uses a genetic algorithm (Rutkovskaya et al., 2006), (Sivanandam and Deepa, 2007), (Zvaigzne et al., 2017). To account for constraints, the method of penalty functions is used.

The Optimization Parameters window (Fig. 3) allows you to set or change the parameters of the genetic algorithm, the initial value of the penalty, the criteria for stopping the solution search, displays the fitness graph. It is possible in the process of finding a solution to use the strategy of elitism by checking the box in the corresponding window.

The values and state of the algorithm parameters used by default are suitable for most problems.

The genetic algorithm (GA) is an optimization method based on the concepts of natural selection and genetics. In this approach, the variables characterizing the solution are represented as a gene in the chromosome. The GA operates a finite set of solutions (the population) - generates new solutions as different combinations of population decisions parts, using operators such as selection, crossover, mutation and inversion. New solutions are positioned in the population in accordance with their position on the surface of the function being studied.

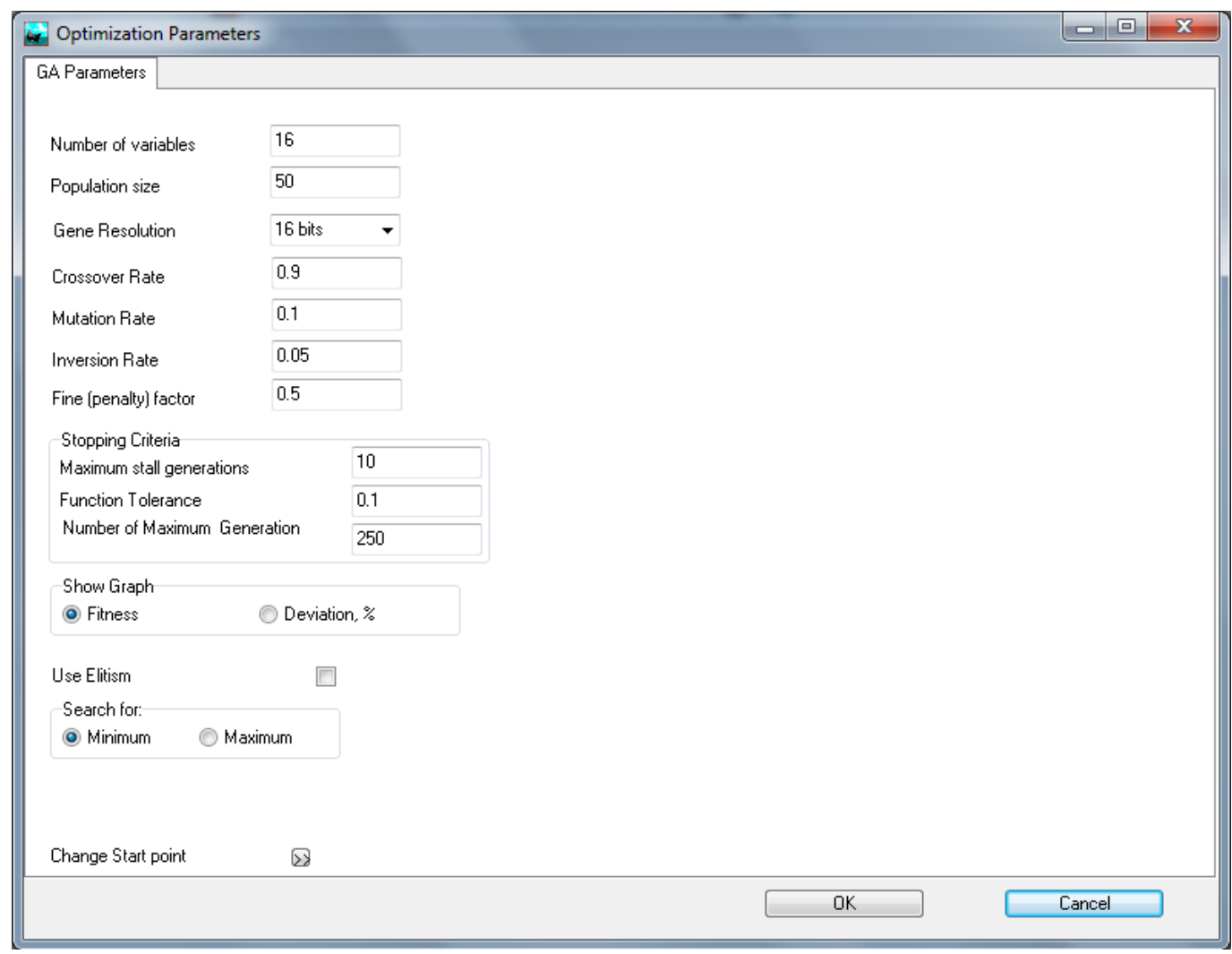

Figure 3. The Optimization Parameters dialog box 

follows:

The optimal solution searching general scheme using a genetic algorithm can be represented as

1. To generate $N$ individuals initial population.

2. To measure chromosomes fitness in the population on the basis of the fitness function. The value of fitness function is determined by the formula:

$$
F_{l}\left(X, C, r_{l}\right)=F(X, C) \pm \sum_{j=1}^{k}\left[\frac{g_{j}^{+}(X)}{r_{l}}\right]^{n}
$$

where $r_{l}$ is the penalty coefficient, which value decreases from one stage to another; $l$ is calculating optimization process generation number; $n$ is the degree, in this research $n=2 ; \sum_{j=1}^{k}\left[\frac{g_{j}^{+}(X)}{r_{l}}\right]^{n}$ is penalty for constraints violation (penalty function):

$g_{j}^{+}=\left\{\begin{array}{l}\max \left\{g_{j}(X) ; 0\right\}, j \in[p+1, k] \\ \left|g_{j}(X), j \in[1, p]\right|\end{array}\right.$.

$F(X, C)$ - indicator of the efficiency of the tug fleet (the minimum total bollard pull, minimum operating costs, net profit).

For example, the total bollard pull of tugs is calculated by the formula:

$F(X, C)=\sum_{i=1}^{n} Z_{i} N_{i}$

To solve the problem of choosing the optimal number of harbour tugs, the following set of constraints $g$ is used:

- the required total bollard pull of the tugs involved in the mooring operation should be no more than the actual bollard pull of the selected tug;

- the number of tugs engaged in the mooring operation must be at least two and not more than five;

- in one mooring operation it is acceptable to use tugs only from approximate groups (limitation on bollard pull).

While using the genetic algorithm, the independent variables boundary values $\left(x_{i}^{\min }, x_{i}^{\max }\right)$ do not participate in the penalty functions creation, since they are used in encoding/decoding of independent variables (an independent variable will always be in the boundary range).

For example, encoding/decoding real-valued independent variable

$c=\frac{\left(x_{i}-x_{i}^{\min }\right)\left(2^{s}-1\right)}{\left(x_{i}^{\max }-x_{i}^{\min }\right)}$.

The received value $\mathrm{c}$ with is transferred to a binary system, decoding

$x_{i}=\frac{d_{i}\left(x_{i}^{\max }-x_{i}^{\min }\right)}{2^{s}-1}+x_{i}^{\min }$,

$x_{i}^{\min }, x_{i}^{\max }$ - are lower and upper bounds on the independent variable;

$s$ - is the number of bits per one element of chromosome (gene);

$x_{i}$ - is the decoded real value from bit string of lengths;

$c$ - is the coding representations of $x_{i}$;

$d$ - is the decimal value of the sub-string corresponding to $x_{i}$.

3. To perform the selection operation, i.e. for each agent of the new generation to select two parents from the current generation in proportion to fitness. 
4. For selected parents to create candidates for the new population creation using genetic operators (mutations, crosses, inversions).

5. To create a new population.

6. If the criterion for stopping the algorithm is done, then finish the search, otherwise - to do the iteration search next cycle.

To create a new population, the so-called genetic operators are used: selection, crossover, mutation, inversion.

The selection of individuals (parents) involved in the creation of offspring is done using selection operators. There are several options of selection mechanism realization: roulette-wheel selection, tournament selection, ranking selection etc. In this article the tournament selection in which all populations are divided into subgroups that consist of two individuals is used by authors. Then the individuals with the best fitness are selected in each of these subgroups.

Crossover operation is used to change the composition of the population. In the genetic algorithm, a crossover (in the literature on genetic algorithms, the name crossing-over or crossing is also used) is an operation in which one or more new chromosomes are generated from two chromosomes.

It operates as follows:

- two individuals are selected from the population to be parents;

- the point of discontinuity is determined (usually randomly).

The child is defined as the concatenation of a part of the first and second parent. The probability of a crossover is usually chosen rather large, of the order of $80-95 \%$.

The mutation operator is designed to maintain a variety of individuals in the population. The mutation operation changes the values of genes in chromosomes with a given probability $p_{m}$. This leads to inverting the values of the selected genes from 0 to 1 and back. The value $p_{m}$ is usually very small, so only a small number of genes are mutated. The probability of a mutation is usually assumed to be of the order of $0.5-1.0 \%$. places.

The inversion operation is that the chromosome is divided into two parts, and then they change

The elitism strategy is that individuals with the greatest fitness are guaranteed to move into a new population. The use of elitism usually allows us to accelerate the convergence of the genetic algorithm.

At new population creation, either a complete replacement or a partial replacement of the previous generation is possible, at which part of the population goes into the next generation without changes, i.e. the chromosomes of this part are not exposed to the crossing and mutation operations (the elitism strategy).

The new population creation corresponds to the genetic algorithm one iteration.

As a search completing criterion can be:

- generations given limiting number achievement;

- time set period expiration;

- fitness function values stabilization (lack of fitness function values changes);

- good enough solution getting.

As a result of modelling the evolutionary process with the genetic algorithm help, we get the most adapted individual, i.e. the optimization problem solution.

Then the solution search process is started.

After the search is completed, the independent variables vector components - a different bollard pull forces tugs number and their number for each bollard pull determining the optimal composition of the port's tug fleet are displayed in the results dialog box.

The main advantage - the choice of the optimal composition of the tug fleet for the port is made in a wide range of standard sizes of tugs. The disadvantage of the method is a long procedure for obtaining the result.

At the same time, both methods give close results if, with the help of the first one, several options are considered for the composition of the port's tug fleet, ranked by economic efficiency indicators.

\subsection{Calculation result}

The program has successfully passed testing, which includes comparison of modelling data with the Yuzhny port tug fleet work data. 
The optimization problem of the towing support of the port "Yuzhny" was considered for two options: the existing berth complex and the berth complex of the future.

The first option: which tugs of the port will ensure the greatest efficiency of mooring operations on the order of 1180 vessels per year to the existing berths of the port. The efficiency of the port fleet was estimated by the annual profit.

The second option involved the determination of required number and characteristics of harbour tugs for the port of "Yuzhny", taking into account its development. The development of the port assumed the putting into operation of 6 new berths and an increase in the number of calls to the port to 1,400 ships per year.

For both options, three versions of tugboat service were proposed:

1) the existing composition of tugs ("Equator", "Boreas", "Nord", "Yakovtsev", "Saveliev", "UTN", "Ivanov", "Moguchiy"); 75 tons;

2) except for the existing tug structure of the most powerful tug "Moguchiy" with a bollard pull of

3) except for the existing tug composition of two tugs "Moguchiy" with bollard pull of 50 and 75 tons, but the addition of a tug "UTN", "Stan tug 1907" with a bollard pull of 30 tons.

The main indicators of the efficiency of the tug fleet, as well as the annual distribution of participation of each tug in mooring operations for various options are presented in Table 2.

Table 2. Results of solving optimization problems for the existing berthing complex and the complex of berths of the nearest future port «Yuzhny»

\begin{tabular}{|c|c|c|c|c|c|c|c|}
\hline \multirow{2}{*}{ Tug name } & \multirow{2}{*}{ 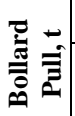 } & \multicolumn{3}{|c|}{ The existing complex of berths } & \multicolumn{3}{|c|}{ Future berths complex } \\
\hline & & Option 1 & Option 2 & Option 3 & Option 1 & Option 2 & Option 3 \\
\hline $\begin{array}{l}\text { Equator and } \\
\text { other }\end{array}$ & 3 & 799 & 816 & 793 & 830 & 843 & 865 \\
\hline Boreas & 16 & 1172 & 1191 & 1189 & 1282 & 1323 & 1314 \\
\hline Nord & 20 & 944 & 982 & 861 & 1141 & 1193 & 1031 \\
\hline Stan tug 1907 & 30 & - & - & 786 & - & - & 974 \\
\hline Yakovtsev & 50 & 809 & 854 & 585 & 997 & 1016 & 738 \\
\hline Saveliev & 50 & 537 & 541 & 407 & 719 & 757 & 553 \\
\hline UTN & 50 & 392 & 381 & - & 542 & 582 & - \\
\hline Ivanov & 65 & 220 & 150 & 159 & 340 & 254 & 236 \\
\hline Moguchiy & 75 & 76 & - & - & 105 & - & - \\
\hline Total & & 4949 & 4915 & 3987 & 5956 & 5968 & 5711 \\
\hline Vessels number & & 1180 & 1172 & 1176 & 1403 & 1398 & 1400 \\
\hline \multicolumn{8}{|c|}{ Economic characteristics, million UAH } \\
\hline Operating costs & & 62.32 & 50.39 & 46.00 & 68.71 & 57.85 & 51.42 \\
\hline Incomes & & 113.04 & 110.80 & 113.07 & 134.67 & 137.96 & 128.02 \\
\hline Net profit & & 50.72 & 60.42 & 67.07 & 65.96 & 80.11 & 76.59 \\
\hline
\end{tabular}

For the existing berthing complex with the existing tug structure, the most profitable is the option 3 (removal of two tugs with bollard pulls of 50 and 75 tons compensated by the addition of a tug with a bollard pull of 30 tons). Annual net profit is 67.07 million UAH. For the perspective complex of berths option 2 (removal of only one powerful tug with a bollard pull of 75 tons). Net profit 80.11 million UAH...

The calculation of the annual employment of tugs in mooring operations for the existing berth complex (option 3) is shown in Figure 4. 


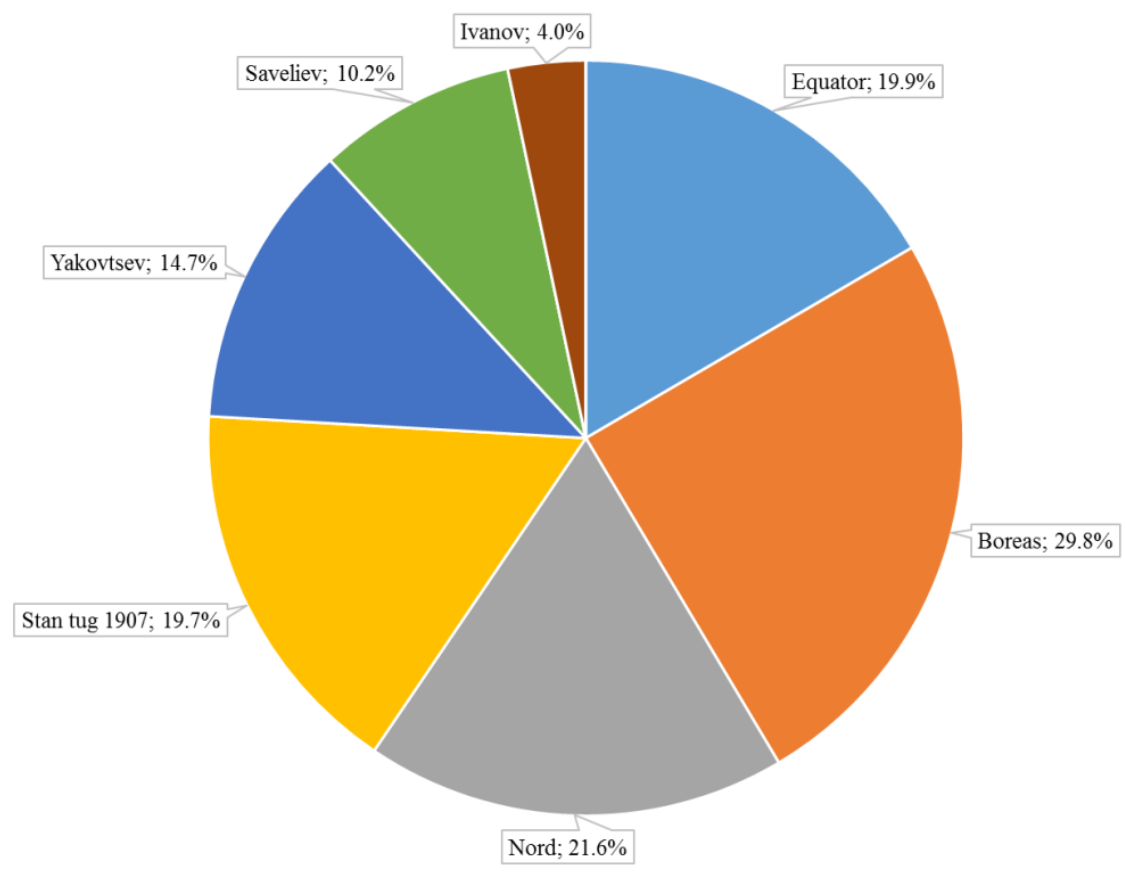

Figure 4. Annual employment of tugboats in mooring operations

\section{Conclusions}

For port tug support the algorithm of estimation efficiency and optimization of the composition of port tug fleet criteria for achieving, as a result of mooring operations, the minimum of the fleet total bollard pull and the maximum of its productivity. The application of this algorithm helps to increase the competitiveness of the ports' departments occupied with tugs operation.

Determination of the optimal characteristics of tugboats and the tug port fleet composition has been carried out by solving optimization problem with using genetic algorithm. This algorithm was done in the form of a software product that provides:

- optimization of the composition of the existing or updated towage of the port by the tugs types and the bollard pull developed by them, carried out in accordance with the characteristics of the port water area and approaches to it, the port quay walls number and the port equipment production;

- determination of the vessels safe servicing economic results in the complex of existing or expanded berths of the port by the existing or designated tug fleet;

- solution of the tugs designing main problems, in particular - creation of a number of such vessels dimensions depending on the required bollard pull.

The results taken during search are proposed to use for optimization of the composition of the existing or updated port tug providing, selecting the design characteristics of the port tugs. be used:

Perhaps there is another application of the algorithm and software complex. Particularly, they can

- for the operational resolve of all current problems of the escort maintenance and mooring / unmooring of ships in the modern port with using powerful tugs;

- for the formation of norms or the establishment of a minimum quantitative composition of tugs when doing mooring operations in the specific port.

\section{References}

1. Alyavdina, T.F. (1986) Development of Procedures for the Selection of Optimal Types and Number of Tugs for the Port, Cand. Diss. Leningrad, USSR.

2. Bondarenko, O.V., Nekrasov, V.O. and Yastreba, O.P. (2016) Effectiveness harbour tug fleet: problem formulation and methodology of its solution. Brodogradnja /Shipbuilding: Theory and Practice of Naval Architecture, Marine Engineering and Ocean Engineering, 67, 33-46.

3. Chan, V. (2013) Theory and Applications of Monte Carlo Simulations, InTech. 
4. Gnedenko, B.V. and Kovalenko, I.N. (2007) Introduction to Queuing Theory. Moscow: Izdatelstvo LKI.

5. Hensen, H. (2003a) Using experience to asses required tug power. Port Technology International, 26, 95-97.

6. Hensen, H. (2003b) Tug use in port. A practical guide, 2nd ed. Port Rotterdam: Nautical Institute.

7. IMO, (2003) Ship/Port Interface. Availability of tug assistance, Ref. T3/3.01, 8 Sept.

8. Law, A.M. (2015) Simulation Modelling and Analysis, 5th ed. New York: McGraw-Hill Publ.

9. Lewandowski, E.M. (2003) The Dynamics of Marine Craft: Maneuvering and Seakeeping. Singapore: World Scientific Pub Co Inc.

10. Rutkovskaya, D., Pilinskiy, M., Rytkovskiy, L. (2006) Neural Networks, Genetic Algorithms and Fuzzy Systems. Moscow: Goryachaya liniya - Telekom Publ.

11. Saaty, T.L. (1961) Elements of Queuing Theory with Applications. New York: McGraw-Hill.

12. Sivanandam, S.N. and Deepa, S.N. (2007) Introduction to Genetic Algorithms. New York: Springer Publ.

13. Stewart, W.J. (2009) Probability, Markov Chains, Queues, and Simulation: The Mathematical Basis of Performance Modelling, Princeton University Press.

14. Zvaigzne, A., Bondarenko, O. and Boiko, A. (2017) Decision support system on the base of genetic algorithm for optimal design of a specialized maritime platform, Computer Modelling \& New Technologies, 21, 11-18. 